\title{
“I Feel We are Inclusive Enough": Examining Swimming Coaches' Understandings of Inclusion and Disability
}

\author{
Andrew Hammond \\ University of British Columbia \\ Ruth Jeanes \\ Monash University, Melbourne \\ Dawn Penney \\ Deana Leahy \\ Edith Cowan University and Monash University, Melbourne \\ Monash University, Melbourne
}

\begin{abstract}
In this study, semi-structured interviews were conducted with eight Victorian swimming coaches to examine the discourses of disability ${ }^{1}$ and inclusion that they expressed in relation to their current coaching practices. Analysis specifically pursued links between neoliberalism, ableism, elitism, classification and inclusion in coaching, with the intention of exploring what discourse relations are possible, imaginable and practical within what have been referred to as neoliberal-ableist times. Findings reveal that coaches replicate and reproduce elitist, ableist assumptions about the body and sport. The discussion prompts a consideration of how rationalities and techniques of inclusion are limited under the prevailing political context.
\end{abstract}

This paper explores the effects of "neoliberal-able rationality" sport policy and swimming coaches' understandings of inclusion and disability. Recent research has highlighted how economic policies underpinned by neoliberal rationalities of government often see sport as a tool that can be used to alleviate social problems that are conceived to be a social and economic burden on the state (e.g., juvenile delinquency, obesity, homelessness, unemployment and so on) (Gard, Dionigi, \& Dionigi, 2018; Hall, 2006; Parnell, May, Widdop, Cope, \& Bailey, 2018). Our research specifically responds to Bush and Silk's (2012) call to critically examine how neoliberal governing rationalities influence coaches' thoughts and beliefs of inclusion in the disability context. We draw on the work of Goodley and his critical concept of neoliberal-ableism (i.e., the fusion of the concepts of neoliberalism and ableism) to explore how these rationalities infect coaching policies and practices related to inclusion in the sports coaching sub-culture of Victorian swimming. Goodley (2017) defines neoliberal-ableism as a "state of economic, cultural and political life" where people who can only participate in society if they "manage to demonstrate normalcy and abilities to become part of the capitalist marketplace, ready and willing to work" (p. 177). How our theorization of neoliberalableism was defined and applied as a central concept in this study is expanded upon in the sections that follow.

The paper reports findings arising from a qualitative study involving eight club-level coaches in the state of Victoria, Australia. The aim of this research was to explore how coaches understood inclusion and disability in relation to their practice, and how contemporary neoliberal-able rationalities of government influenced these understandings. The analysis and discussion that we present explores the limitations of current rationalities and techniques of inclusion, as expressed by the participants, under the prevailing conditions of neoliberal-ableism. The following sections address the concepts of neoliberalism and ableism that are central to this research and then expand upon our theorization and application of the concept of neoliberal-ableism to critically examine sport and inclusion.

\section{Neoliberalism}

We define neoliberal rationality as a governing rationality through which everything becomes "economized." As Wendy Brown has explained, neoliberalism is an undertaking of governmentality (Foucault's term) where:

human beings become market actors and nothing but, every field of activity is seen as a market, and every entity (whether public or private, whether person, business, or state) is governed as a firm. Importantly, this is not simply a matter of extending commodification and monetization everywherethat's the old Marxist depiction of capital's transformation of everyday life. Neoliberalism construes even non-wealth generating spheres-such as learning, dating, or exercising-in market terms, submits them to market metrics, and governs them with market techniques and practices. Above all, it casts people as human capital who must constantly tend to their own present and future value (Brown cited in: Shenk, 2015, para 6).

We acknowledge that neoliberalism has never been one logical, sound doctrine, and that the concept has had many iterations (Brown, 2018). We have drawn on neoliberalism to emphasize that market-based thinking elevates the rights and political concern of individuals and families over the collective "will of the people" (i.e., policies for tax cuts coupled with austerity in the public sphere and the weakening of democracy) (Brown, 2015, 2018). Therefore, a key problem with neoliberal rationalities of government is that through an emphasis on market values such as competition, they create fertile ground for austerity policies that seem to

Hammond is with the School of Kinesiology, University of British Columbia, Vancouver, Canada. Jeanes, Penney, and Leahy are with the Faculty of Education, Monash University, Melbourne, Australia. Penney is also with the School of Education, Edith Cowan University, Perth, Australia. Address author correspondence to Andrew Hammond at andrew.hammond@ubc.ca. 
disproportionally affect those in our community who are acutely marginalized (such as people with disabilities, people of color, women) (Dean, 1995, 2010; Goodley, 2014; Goodley, Lawthom, \& Runswick-Cole, 2014). Our research has explored how neoliberal rationalities of government produce particular kinds of coaching subjectivities and coaching practices that are framed in relation to market terms and market metrics. It has sought to illustrate why this is problematic from a disability inclusion perspective.

\section{Ableism}

Alongside the application of neoliberalism, we apply an ableist lens to examine coaches' interpretations and understandings of inclusion. We specifically draw on Kumari Campbell's definition of ableism to define the concept as:

a network of beliefs, processes and practices that produce a particular kind of self and body (the corporeal standard) that is projected as the perfect, species-typical and therefore essential and fully human. Disability, then, is cast as a diminished state of being human (Kumari Campbell, 2001, p. 44).

Goodley (2014) suggests that by problematizing disability against the background of ableism, disability emerges as a site of otherness and marginality in conjunction with other identities, performances, and processes (including those relating to ethnicity, class, gender, sexuality, and pan-national identities). Ableism thus allows us to make "visible" norms that are often invisible (DePauw, 1997; Kumari Campbell, 2009; Wickman, 2007). In this study we use ableism to help explain why disabled people are often excluded and marginalized from sport structures and why an elite few disabled people become included. We suggest that in order to understand how ableism functions in sport, we also have to grasp how the current politics of neoliberalism links with schemas of ableism to produce neoliberal-able governing rationalities that powerfully shape the field of possibility for coaches and their practice.

\section{Neoliberal-Ableism}

According to Goodley, normalcy equates to economic viability. As Goodley et al. (2014) explain,

neoliberalism provides an ecosystem for the nourishment of ableism, which we can define as neoliberal-ableism. We are all expected to overcome economic downturn and respond to austerity through adhering to ableism's ideals, its narrow conceptions of personhood, its arrogance and its propensity to buddy-up with other fascistic ideologies that celebrate the minority over the majority means that it is a world-view, an ontology and a methodology for the making human-kinds that will eventually, if left unchallenged, bulldoze the disparate variegated nature of human kind (Goodley et al., 2014, p. 981).

Following Goodley et al. we suggest that those who are most likely to participate in society (and sport) are the most abled of the disabled. Analyses of the effects of policies produced under neoliberal rationalities of government in Australia reveal the privileging of the 'abled disabled' (Hammond \& Jeanes, 2018; Jeanes et al., 2019). Thus, in this study, we apply the concept of neoliberal-ableism to inform exploration of how coaches choose which disabled athletes they "include," how they do so, and why they make the choices that they do.

The disability studies literature has illustrated that people with disabilities are often seen or viewed as a "drain" on public resources (Goodley, 2017; Goodley \& Runswick-Cole, 2015). As Goodley (2017) suggests "the demands of ableism fit the discourse of neoliberalism - each feeding off one another to incite individual accountability and reduced state support, to be capable and self-sufficient," (p. 117). In this research we borrow from Goodley (2014) to highlight how neoliberalism is inextricably linked to regimes of ableism and how the tenets of neoliberalableism specifically produce but also limit the conditions of possibilities (Leahy, 2012) for inclusive coaching in the context of Victorian swimming. In the following section we discuss how inclusion has come to be theorized and enacted in neoliberal-able times particularly within sports contexts.

\section{Sport Under the Conditions of Neoliberal-Ableism}

In this paper we explore how coaches in Victoria variously reenforced and, in some instances, productively "resisted" the invisible normativity produced by neoliberal-ableist rationalities that Wickman (2007) and others have described. The effects of neoliberal-able rationalities sensitize us to the realities and limitations of inclusion under these conditions.

Under the conditions of neoliberal-ableism, inclusion policies often illustrate a utopian vision whereby anyone can be included, but in practice due to the emphasis on market-based values who can become included is often very narrow. Following Miller and Rose (2008) these optimistic (they argue government is endlessly optimistic) "utopian visions" will inevitably perpetually fail. For instance, in their study, Hammond and Jeanes (2018) highlighted that these optimistic utopian visions (Miller and Rose's term) of inclusion led to the most abled athletes being privileged within disability sport, as they were most likely to meet external standards of normalcy. We argue that under the conditions of neoliberal-able rationality sport can only ever produce what Barton (1997) has referred to as integration, as opposed to a more progressive and subversive form of inclusion:

[Inclusion] is about responding to diversity; it is about listening to unfamiliar voices, being open, empowering all members and about celebrating 'difference' in dignified ways. From this perspective, the goal is not to leave anyone out of education. Inclusive experience is about learning to live with one another. This raises the question of what [inclusive sport] is for. They must not - as was the case with many definitions of integration [. . . be about assimilation in which a process of accommodation leaves [sport] remaining essentially unchanged (Barton, 1997, p. 234).

Sociologists of sport have revealed how ableism is a guiding framework for how disability sport is organized in many settings. For example, Jeanes et al $(2017 ; 2018)$ have illustrated how community sports clubs tend to support the inclusion of participants with a disability who can most readily fit into their existing structures and systems. In Jeanes et al's studies, this was individuals with a mild or moderate intellectual disability who did not require the club to significantly adapt how they ran and delivered their sport. Kitchen and Howe (2014) highlight similar issues in English cricket, suggesting that the policy of mainstreaming within sport is underpinned by ableist logic that means all disabled athletes have to seek to achieve able bodied norms and standards. Wickman (2007), again applying an ableist lens, suggests that the subject of "disabled athlete" is viewed by coaches and athletes as deviant in relation to the invisibility of "able-bodied" norms. Furthermore, she argued that ableist discourses influenced athletes' identities and 
their world views, and, they embodied and spoke the discourses of able-bodied people in order to pass standards of normalcy in relation to sporting and gender discourses. In Wickman's study, athletes with disability would refer to themselves as wheelchair racers rather than as disabled athletes, to position themselves as elite athletes. In their historical study of ableism, Hammond and Jeanes (2018) followed Wickham in arguing that the evolution of disability and mainstreaming policies has resulted "in a series of truths that legitimize, conceal, and neutralize exclusion through the 'dividing practices' of regulation and differentiation," (Hammond \& Jeanes, 2018, p. 3).

As we stated above, people with disabilities are often seen or viewed as a "drain" on public resources (Goodley, 2017; Goodley \& Runswick-Cole, 2015) and sport is seen as one way of making the disabled body more productive through sport based rehabilitation and training (Howe \& Jones, 2006; Howe \& Silva, 2017; Jones \& Howe, 2005; Purdue \& Howe, 2013). Thus disability sport, is one "technology of government available" for disabled people to overcome "adversity" associated with their impairment (Braye, Dixon, \& Gibbons, 2013), and arguably coaches work in sport is essential to supporting these objectives and thus re-enforcing and sustaining damaging "super crip narratives"" (e.g., Schalk, 2016; Shapiro, 1994). Briefly, the reason why super crip narratives are so harmful is because they suggest that through sheer grit and determination, people can 'overcome their disabilities' to become capable and self-sufficient members of society who are able to rid themselves of state-support (Braye et al., 2013; Wedgwood, 2014). Silva and Howe (2012) also argue that this serves to re-impose "society's low-level expectation placed upon people with disability, which ultimately perpetuates the understanding of their existence as a 'problem,"' (p. 175). Thus, following Jeanes et al (2017, 2018) we contend that sport continues to be an environment within which ableism is internalized and hence, flourishes, as sport produces narratives where people overcome their disabilities to become capable and self-sufficient members of society who are able to rid themselves of state-support in line with neoliberal-able policy imperatives (Braye et al., 2013; Wedgwood, 2014).

In the next section we provide essential background about Australian swimming before using the critical disability studies concept of neoliberal-ableism to critique the schema of classification. As we explain, through our theorization of neoliberal-ableism, classification is conceptualized as a series of truths leading to dividing practices that legitimize, conceal, and neutralize limited forms of inclusion in Victorian and world swimming.

\section{Australian Swimming: Participation, Performance and Professionalism}

In the history of Australian swimming, discourses of commodification, economization and professionalization are intertwined with those of participation, elitism and performance. Indeed, Australian swimming has a long history of charging individuals for access (Phillips, 2008), with the practice of professional swimming coaches and trainers charging fees for service pre-dating Australian Federation in 1901 and reflecting a strong colonial tradition of gambling on swimming races (Phillips, 2000, 2008). In contemporary times, the 'swimming coaching industry' in Australia has established performance measures as a means of justifying coaching salaries and fees (Zehntner, 2016). Pertinent to this research is the intensification of the economization of swimming that has occurred under the conditions of neoliberal-ableism. As Zehntner's
(2016) analysis has highlighted, fees and salaries throughout Australian swimming are now inextricably linked to performance agendas and attainment of medals at competition. Many coaches now expect to earn professional salaries (particularly in the metropolitan areas of Melbourne, Brisbane and Sydney) that justify the grueling demands (e.g., Zehntner, 2016) of coaching swimmers along the development pathway (Green \& Houlihan, 2005). As Zehntner (2016) has also shown, swimming at the community level in Australia is largely directed towards developing elite swimmers, who are expected to win medals, which in turn provides a justification for the fees set by coaches and pools.

In this study all coaches were "Victorian" (i.e., they live and coach in the state of Victoria in Australia). While Victoria is Australia's second most populous state, fewer people participate in swimming and there is less public pool space due to the more temperate climate. ${ }^{3}$ Furthermore, many swimming facilities are owned and operated by elite private schools that limit public participation (Green \& Houlihan, 2005). As we discuss further below, within the discursive net of neoliberal-ableism, coaches in this study faced notable precarity in their positions due to a scarce supply of pool space. This subsequently lead to the need for coaches to justify pool time as a through the promise of performance. In the following sections, we expand on research engaging with disability swimming coaching in Australia and classification. We highlight necessary background information on classification before arguing how under the conditions of neoliberal-ableism classification is one of the many necessary techniques of neoliberal governance that serves to contribute to the maintenance of ableist assumptions and structure of competitive swimming.

\section{Classification, Disability Sport and Swimming}

Classification is key to governing populations, and as a technique it serves both biopolitical and governmental purposes (see Foucault, 1991; Foucault, Davidson, \& Burchell, 2008). In the field of disability swimming classification is a key way that dominant ableist structures are maintained and reproduced. To help us understand how classification functions here as a technique of the neo-liberal ableist project, we draw on both the field of governmentality studies and literature that foregrounds the cultural politics of disability sport (DePauw, 1997; Goggin \& Newell, 2000; Howe, 2008a; Howe \& Kitchin, 2017; Shogan, 1998, 1999). Much of this research has sought to locate the impact of classification policies and discourses amidst the broader neoliberal-ableist project of sport (Bush \& Silk, 2012; Hayhurst, Wilson, \& Frisby, 2010; Horne, 2005). Classification, within this frame, can be understood to be a necessary taxonomy for the organization of competitive disabled?? swimming. It is significant in that it contributes to the broader conditions of possibility that coaches function in. As Howe (2008b) has stated elsewhere, classification is the term used to refer to the system via which athletes with a disability are categorized and distinguished from one another with the intention that they compete on a "level playing field" (Howe, 2008b, p. 500) with other athletes with comparable impairments. Howe and Kitchin (2017) suggest that in simple terms classification involves three steps that relate to these questions:

1. Does the athlete have an eligible impairment for this sport?

2. Does the athlete's eligible impairment meet the minimum disability criteria of the sport?

3. Which sport class describes the athlete's activity limitation most accurately?

(Howe \& Kitchin, 2017, p. 114). 
The functional classification system that swimming adopted in the 1990s divides athletes into classes based on functional ability in classes based on impairment type (Tweedy, Beckman, \& Connick, 2014); classes can be broadly defined as physical (S/SM/SB1-10), visual (S/SM/SB11-13) and intellectual (S/SM/SB14) impairment (Swimming Australia, 2013). ${ }^{4}$

Proponents of functional classification such as Richer et al. (1992), acknowledge that while the system was not perfect it allowed for the reduction of classes (i.e., functional classification allowed for a smaller number of events to be held at Paralympic events) and a better spectator experience. Furthermore, Richer et al. (1992) forecasted that the shift towards functional classification in swimming would make the sport more commercially viable (such as through the selling of television rights), and alleviate spectator confusion about multiple events, but that this would come at the expense of restricting and narrowing eligibility for competition for a broad range of people with disabilities (due to an overall reduction in classes) (Howe, 2008a). Richer et al's (1992) predictions that disability sport will increase in commercial viability appears to have been realized (Howe, 2008a). Similarly, his belief that Paralympic sport would become more exclusionary has also eventuated. Howe (2008a) has highlighted how functional classification allowed for a framework of competition that led to the reduction of classes, and the reduction of people with more complex impairments (such as those with Cerebral palsy in athletics) participating in Paralympic sport. More specifically, for this study, the issue is that if classification is uncritically questioned and implemented as the dominant organizing model of Paralympic sport at the grass roots level, inclusivity and equity will be diminished (Howe, 2008b; Howe \& Silva, 2017; Richter, Adams-Mushett, Ferrara, \& McCann, 1992). For example, the literature on swimming coaching has seldom explored how classification influences coaches working at the club and development level (cf. Cregan, Bloom, \& Reid, 2007).

To summarize, in swimming (Cregan et al., 2007), and other sports, eligibility for classification and the process of classification itself effectively constrains who can participate in disability sport, on what basis, and which other athletes with disabilities can participate (Howe, 2008a, 2008b; Howe \& Kitchin, 2017; Howe \& Silva, 2017). Howe (2008b) contends that a key problem with classification is that elite Paralympic based models of sport are exclusionary. Howe (2008b) has argued specifically that:

an increase in the severity of the disability is directly linked to the marginality felt by individuals within sporting practice. In other words, greater impairment equates to lesser acceptance for a sportsperson. The Paralympic athletes that receive the greatest exposure are in fact the most 'able', that is, the least impaired (Howe, 2008b, pp. 213-214).

Howe and Silva (2017) suggest that it not the intention of the International Paralympic committee and other elite sporting bodies to make elite Paralympic sport inclusive, and this is why we have to problematize how inclusion is understood and enacted and not just assume it is inherently good. As we highlighted above, neoliberalable rationalities of government can only ever produce limited forms of inclusion. Given this, we are concerned with how these discourses permeate the participation development and sub-elite organization of the sport, and more particularly, how they are embedded and reflected in coaches' practices. Bush and Silk (2012) noted that experiences of disability sport coaches raise "a number of important questions about the structure of 'coach education,' the role of the coach, the hierarchies within disabled sport, the impact of commodification on the disabled body and the (perceived) barriers to physical activity for disabled participants" (Bush \& Silk, 2012, p. 481). Moreover, extensive recent research into disability coach education has shown that it is often constructed around impairment, thus reinforcing exclusionary discourses (Townsend, Cushion, \& Smith, 2018).

\section{Methods}

This paper arises from a broader two-phase qualitative study that examined the relationship between disability and inclusion policies and coaching practice (Hammond, 2019). The first phase, centering on policy, took a genealogical approach to tracing the history of the development of government involvement in disability policy in sport in Australia (Hammond, 2019). This paper specifically reports on data from the second phase of the study, that explored coaches' understandings of disability and inclusion in the context of them providing accounts of their experiences of coaching. The study was granted ethical approval by the authors' university Human Ethics committee.

This research represents an initial step into an under researched area. It takes a poststructuralist perspective, foregrounding multiple interpretations of truth, and thus does not claim universal (or positivistic) generalization (Smith, Bundon, \& Best, 2016; Smith \& Sparkes, 2013). It provides constructed insights from coaches about how they conceptualize and articulate notions of inclusion and disability in relation to their practice. Data collection was confined to interviews with coaches and did not extend to athletes (either ablebodies or athletes with a disability) or co-workers, and did not involve observation. The data is therefore presented with full acknowledgement that we are only hearing about experiences of coaching from the coaches' perspectives and that we cannot assume depth of awareness of their own practice (Partington \& Cushion, 2013). Consistent with our poststructuralist stance, we argue that our (or any, for that matter) data collection can only provide only a partial account of enactment of inclusion by Victorian swimming coaches and further research is required to extend the picture generated by this study. We nevertheless propose that the findings presented provide original insights into coaches' understandings and imaginings of disability and inclusion and in doing so, generate an important foundation for further research.

The study used criterion-based sampling (Sparkes \& Smith, 2013) for selecting coaches. Specifically, the study sought participation from coaches who, at the time of data collection (late 2015early 2016) were (a) working in the state of Victoria in Australia; (b) self-reported to have coached an athlete with a disability in the last five years in swimming; and (c) declared they were working (as defined by volunteering, receiving and honorarium, charging fees or salaried) at any level of swimming coaching. In order to recruit participants, the lead author liaised with Swimming Victoria (SV) and the Victorian branch of the Australian Swimming Coaches and Teachers Association (ASCTAV). An email call for participants was sent to a contact at SV who published a fortnightly email newsletter distributed to all coaches in Victoria. The study was advertised in six consecutive newsletters and participants were selected if they voluntarily responded to the advertisement. After the first three advertisements no new coaches came forward. SV and ASCTAV also advertised the study at three events during the recruitment period.

Eight (8) coaches (five who identified as female, three who identified as male) were recruited. Gender balance was not a criterion for recruitment. No coaches in this study were voluntary 
- all were either employed as either a sub-contractor or an employee of a service provider (e.g., private school, swim school, or local government) and all coaches had been coaching for at least five years. Table 1 below provides a summary of key demographic information about the participants.

Semi-structured interviews were used with the intention of enabling key issues to be explored while also affording flexibility to pursue particularities distinct to the individual coaches. Interviews were conducted at the lead authors' University campus at a time convenient for the coaches and lasted between 90-120 minutes. Interviews were tape recorded and transcribed verbatim by the lead author. In the interviews the lead researcher discussed participants' education background and coaching biography, their experiences of coaching people with a disability, how their educative experiences and life events led to their involvement in coaching, and the challenges and or benefits associated with coaching people with a disability.

A discourse analysis of the eight transcripts following the flexible guidelines set by (Arribas-Ayllon \& Walkerdine, 2010) was undertaken. This allowed identification of the dominant and subjugated discourses of disability and inclusion within the data set. Arribas-Ayllon and Walkerdine (2010) concepts of problematizations, technologies, subject positions, and subjectification were used as deductive codes. First, we identified when the coach discussed disability or a person with disability or inclusion (i.e., problematizations) and then examined how those concepts were organised and presented (i.e., by identifying technologies, subject positions, and subjectification). We then connected those corresponding theoretical statements into themes that linked the individual discourses that structure the fields under investigation. Finally, we connected those discourses specific to the field to the power relations that define the field (i.e., subject positions). The exploration of operations of power from transmissions and transformations of discourse formed the final phase of the analysis (i.e., subjectification). To fulfill the aims of the research and engage directly with the research questions, we then divided the data representations into two key themes, coaches' understandings of disability; and; the implications of this for their interpretation of inclusion.

\section{Findings}

Within the first findings section we focus on how coaches understood disability and highlight how classification was central to their interpretations of disability. In the second part, we examine how coaches' understanding of disability limit and enable imaginings of inclusion in relation to the current structure of disability swimming in Australia.

\section{Coaches' Understandings of Disability}

The eight coaches in this study rarely described their athletes' disability but instead discussed them as having "higher level classifications," such that they had and/or were perceived to have less complex needs. That is, athletes could swim all four strokes independently and could keep pace with other swimmers that they trained with. Typically, they did not require their own dedicated space and/ or an extra coach in order to participate. Thus, coaches "included" swimmers who required very few modifications to be made to their normal coaching practices. The majority of the coaches therefore viewed their role as 'adding' disability to existing programs. Athletes were independent and self-sufficient and not perceived to be as "dependent" in line with inclusion rationalities and techniques associated with neoliberal-ableism (Goodley, 2014, 2017).

Overall, disability was commonly understood as something that was caused by an impairment that led to a reduction of movement or as a "condition" that required special needs or (relatively minor) modifications to the sport. Coaches divided disability types in to a binary_- "physical" and "cognitive." Moreover, it was evident that coaches conflated sensory impairments with intellectual impairments to denote how from their perspective, these impairments influenced the swimmer at the "cognitive" level but otherwise were generally considered physically abled from a motor learning perspective. There was little reflexive discussion about if society or their practice did indeed cause or contribute to an individual experiencing disability rather disability was seen to be a "diminished state of being human," (Kumari Campbell, 2001, p. 44). Thus, those who were included by coaches in this study had to be amenable to reflect ableist norms and standards.

\section{Table 1 Participant and Description of Coaching Context}

\begin{tabular}{|c|c|}
\hline Pseudonym & Description of Coaching Context \\
\hline Carly & $\begin{array}{l}\text { Assistant coach integrated one athlete who had a physical impairment and one who was deaf in her mainstream program. Coach at } \\
\text { community-based swimming club. }\end{array}$ \\
\hline Katie & Head coach who integrated on athlete with intellectual disability into her regular squad. Coach at an elite private girls' school. \\
\hline Bridget & $\begin{array}{l}\text { Special education teacher who ran dedicated swimming squad for school sport and triathlon program. Approximately } 20 \\
\text { swimmers with intellectual disability. Coach employed by government special school running program in community council } \\
\text { owned pools. }\end{array}$ \\
\hline Travis & Coach of one Paralympian with less complex physical disability, lowest classification (S10) at elite private girls' school. \\
\hline Louisa & $\begin{array}{l}\text { Coach of three athletes with physical disabilities included in mainstream groups at community-based swimming club in outer } \\
\text { suburbs of Melbourne. }\end{array}$ \\
\hline Debbie & $\begin{array}{l}\text { Coach of several athletes with varying complexities of impairments of disabilities, she coaches some athletes with physical } \\
\text { disabilities at the lower end of the classification spectrum (i.e., S1-4) as well as others, has a long history of coaching athletes with } \\
\text { a disability in both integrated, inclusive and stand-alone settings, depending on the complexity of athlete's disability and the } \\
\text { individual. She is also an International Paralympic Committee classifier and coaches at a large community-based swimming club. }\end{array}$ \\
\hline Dale & $\begin{array}{l}\text { Dale is currently coaching both athletes with intellectual and physical disabilities. He is a head coach and coached a specialist } \\
\text { disabled program before migrating to Australia. He is a head coach of a community-based swimming club. }\end{array}$ \\
\hline Bailey & $\begin{array}{l}\text { Bailey is involved with both down syndrome swimming and high-level elite level Paralympic swimming. He has coached world } \\
\text { champions in both forms of competition and is a head coach of a swim club in a regional center. }\end{array}$ \\
\hline
\end{tabular}


One of the possible reasons why coaches understood disability as either an intellectual or physical impairment is due to how classification is conceptualized by swimming governing bodies. As Katie explains,

Well yeah, the classification is the big thing and [. . .] if you've got this [impairment] you're classified as this [classification] and you got this so your classified as this and ... if you're a little bit missing two arms, two legs this is your classification compared with missing half an arm- this is your classification ... (Katie)

All coaches in this study made it very clear that they tended to interpret disability through the dominant lens of classification, and as we discuss in the next section, this had implications for who they are including. That is, classification provided all of the coaches in this study with a functional "frame" around which they can design the coaching process linking to technocratic, rationalistic, behaviourist ideals of coaching that allowed for the imposition of abledbodied ideals about the body to remain dominant and prevail (Kumari Campbell, 2009).

The majority of coaches only included athletes who could be "classified" and appeared to have little understanding of disability outside of the schema of classification. Instead they generally understood disability and ability in binary terms, juxtaposed to one another in line with ableist logic. The following is a typical definition of disability in this study,

As either physical or intellectual disabilities [sic], obviously someone's that physical[ly disabled] can't do what an abled bodied [sic] would do and for me that is varied, like someone completely paralyzed compared with someone who has got some sort of movement, whereas the intellectual one, obviously, just people who have learning difficulties, special needs all the way to people who need full-time care (Louisa).

The division of disability types by classes translates into binary understandings of impairments. This binary was problematic because who is able to gain access to classification is contested (Howe, 2008a, 2008b; Howe \& Kitchin, 2017). The schema of classification constrained access in number of ways such as provided the language and discourses for coaches to apprehend how disability related to swimming. That is, classification provides coaches with a functional "frame" around which they can design the coaching process linking to technocratic, rationalistic, behaviorist ideals of coaching; socially constructed ideas of disability do not allow this and so are therefore dismissed (Townsend, Cushion \& Smith, 2018). As Travis' explained in relation to coaching John,

Researcher: So what do you think disability is only related to classification?

Travis: That's a really good question for me classification is a big part of [swimming] and I guess I can only really go on [John] because he is the only athlete I have coached long term but classification leads to performance [and also influences] the training side of it ... so how the disability affects what they can actually 'do' in training. whether that is technique wise .. . the load they can take in kilometers, the intensity that they can train ... not only how that effects that session but sequential sessions.

For Travis, John being classified as an S/SM/SB10 and having cerebral palsy influenced how he understood his disability but also what his body was capable of in training. His comment that "classification leads to performance" was particularly intriguing and telling of the broader conversation and theme across the interviews that unless an athlete could be classified the fact that they had a disability was not of interest to coaches. This is an example of how disabled athletes were only of interest to coaches if they could access competitive pathways, and reaffirms the need for the neoliberal-able coach to justify their legitimacy by producing athletes that can win medals. This was particularly clear when the coaches were asked what they thought about hidden disabilities (i.e., autism, diabetes, eating disorders and so on) or psychosocial disabilities and how these non-classifiable disabilities influenced their practice or approaches towards people with these disabilities. Only Carly (after much prompting and probing) suggested that in her experience of coaching a male athlete with an eating disorder that 'mental health' conditions "could be disabling" but stressing that these non-classifiable disabilities in many instances were treatable illnesses that could be cured by professional experts,

Researcher: Do you see something like that as a disability or is it a separate issue?

Carly: I had one boy who actually struggled with that last year. It was interesting once we worked out what was going on with him what we needed to do about it how much effect did that actually have on his swimming once we got him to see people. he needed to see to start working on that he's obviously ... he's fine with it . . . and everything now so . . . at that point in time I guess you want to think of [his eating disorder as] disabling him ... like in regards to his usual capacity and stuff like that so I'd say you know if you could term something as a short term disability than I guess that would probably come under that umbrella as well ...

Carly's example above highlights how hesitant coaches were to describe a condition that was not "classifiable" as a "disability." This was because of the connotation disability had with classification and performance pathways, anything not a classifiable disability in her eyes was treatable or curable and was not worthy of "disability status" in line with neoliberal-able rationalities (i.e., disability has to link to a performance pathway). For the coaches in this study classification equates to disability, or in Carly's case- the "real" "permanent" disability,

Classification for Bailey was the system, and the truth- but in his eyes it was not perfect. He suggested that Down syndrome athletes were "unfairly" put in the same classification (S14) as "abled-bodied athletes with an intellectual disability" as athletes in this classification who did not have Down syndrome were at an advantage. Likewise, when Carly was asked about how people with psycho-social disabilities (such as mental illnesses) could be included in sport, she responded that all people should be included in sport regardless of their "issue." She also spoke about the difficulties of coaching deaf athletes who, for cultural historical reasons are not included in the classification system that focuses around Paralympic pathways (Brittain, 2016; Howe, 2008a). ${ }^{5}$

While we have discussed some of commonalities that emerged between the eight coaches there was also some divergent thinking at play with regards to how coaches understood disability. Debbie, for example, spoke about how more complex disabilities and/or different types of impairments (intellectual; vs. congenital blindness; blindness developed after sight) influenced how she responded to individual athletes. Debbie insisted that she strived for inclusion where possible, but accepted that in some cases, that 
individuals with more complex disabilities (meaning these athletes required extensive modifications to be included) had to be excluded to be included under the techniques and rationalities of neoliberalable sport. The abled majority could not be disrupted. Debbie explained that in order for athletes with more complex to not disrupt the abled majority, she had to persuade parents/caregivers of these athletes that they required private programs (at a more expensive rate) or the assistance of extra staff in order to be included. In some cases where parents could not afford a private sessions, she would volunteer her time at the end of her scheduled practices to train these athletes. Debbie used Lilly, a swimmer with more complex disabilities as her example of how certain athletes had to be excluded to be included:

Lilly wasn't [someone I could include in mainstream programming], she was one I didn't put into squads, occasionally she would train at the same time bracket as another squad, but the ... hardest thing with the lower classes [read more complex disability] is they're generally, a lot slower, than even your junior swimmer, and they just need more attention and a little bit more specific work ... to what they need. (Debbie)

Debbie also spoke of how she ended a "special session" for a visually impaired swimmer Ben because he didn't have a "physical disability" stating that "he can swim with the squad and everyone can be mindful of where everyone is and which is part of the lane etiquette anyway" (Debbie). Bridget (the only coach that ran dedicated programs for swimmers with intellectual disability) and Debbie also stood out as the only coaches who were invested in exploring how people more likely to be excluded from disability swimming could be included. Debbie organized private lessons and charged parents and/or care givers for her time, whereas Bridget invested "her own money" in paying for extra lanes and assistant coaches at her programs. These coaches seemingly realized that people with disabilities required extra resources in order for them to have the opportunity of participation that would be comparable with that accessible to their less complexly disabled and abled bodied peers. In this context therefore, neoliberal-ableism privileges the most abled of the disabled. Inclusion is only possible if it does not disrupt the abled-bodied hierarchy, and anything beyond this must come at an extra cost to the swimmer or the coach.

Why coaches did not want to be more inclusive was best exemplified by Travis' who argued that he could "be inclusive," but it was beyond the scope of his job role and allocated time to investigate how he could be more inclusive,

it is not a high priority, I would love to be as inclusive as I can but am I going to source out more ways to be inclusive? Unfortunately probably not. Which is just a fact of the job, to be honest ... Maybe it is complacency or what not, but my feeling is we are inclusive enough ... so coming back to your question, sort of broadly speaking, I think a lot more can be done (Travis).

Other coaches' comments indicated that often the onus was on the individual athlete to adapt to the mainstream program, rather than the program being changed to meet individual needs. According to Dale, inclusion was most challenging when a person's disability meant that they could not keep up with "abled bodied" athletes at the same perceived cognitive or social level. He felt that a person with intellectual disability was easier to accommodate

because I can put them in a younger squad group ... they bond really well because they are at that mental level" whereas he lamented that placing "a swimmer who has lost an arm, in a junior group with kids five years younger than them, [doesn't] work well (Dale).

This dilemma of mental versus physical ability was not exclusive to Dale. Carly also spoke of how it was difficult to accommodate her swimmer Sam who was of short stature who had perceived low physical ability but high cognitive and social ability . . .

before entering our squad program and I think initially the other staff probably weren't really sure where to put Sam, cause obviously, being short stature, having shorter limbs all that kind of stuff she's not gonna be able to keep up as well as the other kids within the squad even though she was at a standard which met state qualifying type level. [She] started [...] [in a group] that wasn't appropriate for her because she's like essentially double the kids age in [the junior group] even though swimming ability wise [she was] older than most of the kids in that group she fitted in swimming wise, but not socially, even though she obviously couldn't keep up with most of the time cycles but [in the end I just set] about reducing the amount of distance that she did so she could fit in with the group as much as possible so that you know if you are doing $10 \times 50$ m's or whatever she might go . . not even half way and back just so she can do the repeat cycles with them and always finish at the wall together (Carly)

Although the coaches had different understandings of disability, what was largely absent across the dataset as a whole was any discussion of the social, cultural and individual "felt" and embodied barriers that people with impairments face through engagement in social life. The coaches therefore did not readily draw on discourses aligned with a social relational theorists' conceptualization of disability (Smith \& Bundon, 2017; e.g., Thomas, 2007). Below we discuss further how the prevailing notions of disability in our data linked to classification had implications for the possibilities for inclusion under neoliberal-ableism.

\section{Possibilities of Inclusion Under Neoliberal-Ableism}

In this section we further explore the forms of inclusion that were seen to be possible under the conditions of neoliberal-ableism we have described. For instance, Carly, Travis, Bailey and Katie all spoke about how their most positive experiences of inclusion were when they made minor modifications to the environment and their pedagogies to accommodate people with disabilities. Such modification was what inclusion was articulated to be.

The categorization of people with a disability according to perceived cognitive, social and physical ability was thus central to coaches' understandings of disability and subsequent enactment of inclusion. The interviews further revealed that these understandings were based on their positive experiences of including familiar bodies with particular impairments and aversion was often based on hypothetical disabilities and fear of the unknown. As Carly went on to say, someone with a "massive [read complex] disability" might be potentially challenging to accommodate and disruptive to other swimmers. It became clear that the coaches' understandings of the disabled body were conceptualized in relation to abled bodied norms or what McRuer has described elsewhere as compulsory abled-bodiedness. In that "able-bodied identities, ablebodied perspectives are preferable and what we all are collectively aiming for," (McRuer, 2016, p. 399). Thus swimming is one of the many institutions within our culture that we argue is a showcase for "abled-bodied performance" (McRuer, 2016, p. 400). Furthermore, 
we suggest that swimming coaching and its associated practices aims in part to produce and showcase abled bodied performance as part of a broader neoliberal-able project to produce the capable, autonomous and self-sufficient human subject (Goodley, 2014; Goodley et al., 2014). Under conditions of neoliberal-ableism, that swimmers with disability were positioned as defective. Coaches associated success with occasions when their athletes with disabilities were able to accomplish an able-bodied performance, as eluded to by Bailey and his experiences of coaching his athlete with Down syndrome (Lilly):

Bailey: When I coach I don't consider my swimmers to be disabled, they do exactly the same program as everybody else!

Researcher: They meet the standards?

Bailey: Yep! So I don't have a disabled group and an abled group ... Lilly, who is a Down syndrome girl . . . she does exactly the same program as everybody else, [. . .] she trains with me. She's in the slowest lane [by herself], and she does not stop for the whole session! I know other coaches who work with Down syndrome swimmers, and they're the same. I think when you start to say, 'oh, they're different', you know they need to separate them out, you are not going to achieve what you set out to achieve. Lilly has got ten world records; she has been female swimmer of the meet the last three world championships! . . . I think that's because she trains with my ablebodied squad ... Exactly [the] same program, exactly the same expectations in terms of technique. You have lower expectations on the repeat times, but you don't segregate . . .

The above passage reflects that Bailey was enacting a form of integrative inclusivity that "accepts and legitimizes the presence of difference within society and learning environments through formal institutional modifications" (DeLuca, 2013, p. 330). However, while he recognized Lilly for her differences, compulsory ablebodiedness was the dominant cultural standard that (while impressive) was used by Bailey to judge and accept Lilly's disabled body. Thus, while Lilly was celebrated and perhaps accepted, according to Bailey she has to swim by herself in "the slowest lane at the end of the pool." Lilly is thus integrated into his swimming program, but inclusion in this form seems to both challenge and re-enforce compulsory able-bodiedness. In the light of such data, we argue that inclusion is illusionary, in that ability norms are accepted, reproduced to accommodate disability, but the introduction of disabled bodies into swimming coaching cultures has appeared to have done little to subvert the ableist structures and understanding (re)produced by coaches.

\section{Discussion}

In this paper we have explored the effects of "neoliberal-able rationality" sport policy and swimming coaches' understandings of inclusion and disability, focusing specifically on the broader subcultural context of Victorian swimming coaching. In this section, we discuss how the findings shed light on some of the ways in which contemporary neoliberal rationalities infect policy and practice. We expand upon our theorization and application of the concept of neoliberal-ableism and our finding that in relation to the sport of swimming, classification is a contemporary technique of governance used to regulate disability sport, to discuss how inclusion coaching policy and practice is limited under conditions of neoliberalism. Firstly, we explore how neoliberal-able rationalities restrict sport to the most abled of the disabled and how they re-enforce standards of normalcy.

\section{Neoliberal-Ableism: The Privileging and Production of Normalcy}

In this study, the concept of neoliberal-ableism was used to think about the ways in which coaches choose the disabled athletes they "include," how they do so, and why they make the choices that they do. We found that coaches most value athletes with disabilities when they (hyper)conform to standards of attributes of normalcy and ability in the swimming environment. These were the athletes who were "abled enough" to be included. For example, in Bailey's eyes above, Lilly's ability to be the "same [. . .] as everybody else" is illustrative of how in sport the most abled of the disabled are those who can perform normalcy and abilities and contribute to performance agendas (Jeanes et al., 2017, 2018; Kitchin \& Howe, 2014) and are most valued in the disability swimming context. Thus, a neoliberal-able athlete (with or without disability) who can incite individual accountability and reduced coaching support and "be capable and self-sufficient," (Goodley, 2017, p. 117) was most valued by coaches in this study. Independence and self-sufficiency is arguably a key trait desirable in swimmers in neoliberal-able times and has been highlighted by others who have examined Australian Swimming coaching (e.g., McMahon \& Zehntner, 2014; Zehntner, 2016).

As noted above earlier in the paper, the disability studies literature has illustrated that people with disabilities are often seen or viewed as a "drain" on public resources (Goodley, 2017; Goodley \& Runswick-Cole, 2015). We argued that sport is problematic for people with disabilities because it can lead to the production and legitimization of "super crip" narratives. As we highlight above the privileging of independence and self-sufficiency as desirable values is problematic because those who are not autonomous and independent are reliant on their families (as we showed above) or the "good will" of a small army of champions of change to be included (Jeanes et al., 2017). Thus, there is a need for coaches and swimming programs to think about the responsibility they have as "citizens" to include a broader spectrum of people who might require additional support.

\section{Neoliberal-Ableism: Limited Opportunities for Inclusion}

In this paper we sought to investigate how institutions and coaches in Victoria variously re-enforced and, in some instances, productively "resisted" the invisible normativity produced by neoliberal-ableist rationalities that Wickman (2007) and others have described. We highlighted in the introductory sections of this paper, that under the conditions of neoliberal-ableism, inclusion policies elucidate a utopian vision whereby anyone can be included, but in practice due to the emphasis on market-based values who can become included is often very narrow. Our findings suggest, that the "sport for all" agenda under neoliberal-able governments, certainly in the context of Victorian Swimming, is more about governing people with disability in sport to achieve integrative standards of normalcy rather than creating more inclusive (in Barton's terms) spaces of a more diverse range of people who do not traditionally participate in sport. As was shown above, this is because the model of classification and Paralympic sport that underpins swimming at the grass roots and community level in Australian and Victorian swimming is highly exclusionary (Howe, 2008a, 2008b; Howe \& Silva, 2017; Richter et al., 1992), and in market terms, restricts the supply of 
eligible athletes. Classification here operates as a powerful accomplice of neoliberal-ableism by drawing on distinctive ways of thinking and questioning the taken of granted truths about the disabled body and its sporting capabilities to keep disability swimming the preserve of the most abled of the disabled- or the highly autonomous athlete that assumes a super crip identity.

As we stated in the introduction, ableism is a guiding framework for how disability sport is organized in many settings. Out findings indicate that at a broader level that broader regimes and techniques of inclusion in neoliberal-able times are constraining and limiting. For example, when Carly and Bailey highlighted how they were happy to include and integrate people with disabilities into their mainstream groups, only Debbie saw it as her role to provide appropriate different forms of disability sport provision (sometimes in private) settings in order to cater towards a more diverse range of people with disabilities and those with more complex disabilities. Bridget saw it as her role to use her independent wealth to subsidies her "passion" of providing opportunities for children and teenagers with intellectual disabilities to engage in organized spot and physical activity. In this instance inclusion came at the personal expense of Debbie's time and Bridget's extensive personal financial resources, thus inclusion in neoliberal-able times is only possible for people who have the financial or time capacity to be a champion of change (Jeanes et al., 2017).

Neoliberal-ableism thus allows us to problematize what inclusion is; after all, Australian Swimming consider themselves to be leaders in inclusive sport (e.g., Woods, 2010; Woods, 2015), but our study has shown that it depends on how you define inclusion and who you think should be included. We suggest that under prevailing rationalities of governance, neoliberal-able forms of inclusion can never really be inclusive, because neoliberal-able rationalities of truths are predicated on a series of truths that legitimize, conceal, and neutralize exclusion through the 'dividing practices' of regulation and differentiation, (Hammond \& Jeanes, 2018, p. 3). We argue that even if "providers [i.e., coaches] and participants of sport itself are open and willing to change," (Fitzgerald, 2018, p. 19) that the possibilities of transformation in the neoliberal project of sport appear to be somewhat limited in this current epoch of time.

\section{Concluding Remarks}

Findings from this study have relevance to swimming and debates about disability and inclusive sport in other states in Australia (and indeed the world), but it should be noted that the study looked at the issues of disability and inclusion as they relate to the specific geographical location of metropolitan Melbourne, Victoria, Australia. In thinking of the implications of this study we follow Kitchin and Crossin's (2018) recent sentiments and suggest that Australian Swimming and State Sporting Associations in Australia need to have conversations internally and externally with clubs and coaches about how the integration and mainstreaming of people with disabilities has led to limiting notions of inclusion. We argue than new policy is needed and that this is based on critical reflection of what is understood by "inclusion" and how it might look in this context. To do this Australian Swimming and sporting organizations broadly need to have discussions with coaches, people with disabilities and their families about what can be done to make the sport a more truly inclusive environment and to advise on what policies and procedures are needed to facilitate this. Further, we recognize the need for future research to foreground the perspectives of people with disabilities and their families.

In conclusion, we reaffirm that only by critically engaging and evaluating where we are at present and disrupting some of the "pleasant certitudes" of inclusion discourse (Harwood \& Rasmussen, 2004) is one way that Australian Swimming might inspire more people with disabilities to become involved in swimming (Woods, 2015). This study sought to contribute to such disruption by showing how coaches understood disability and inclusion (as being limited, narrow and superficial) under the broader conditions of possibilities of neoliberalable project of swimming in Victoria, Australia.

\section{Notes}

1. A Note on Language — where possible, we use "person first" terminology (i.e., "people with disabilities"). This is because Australian governments and key Australian disability advocacy groups (e.g., People with Disabilities Australia) consider person first terminology to be least offensive 'by the vast majority of people with a disability' (Department of Human Services, State of Victoria, 2012). However, we also recognize that this terminology is not universal and that it cannot be assumed that all people who experience, or are labeled as disabled, prefer this terminology in Australia (Goggin \& Newell, 2005; Kumari Campbell, 2009; Peers, Spencer-Cavaliere, \& Eales, 2014).

2. Shapiro (1994) defines the supercrip as an "inspirational disabled person [. . .] glorified [. . . and] lavishly lauded in the press and on television" (p. 16).

3. For instance, the median "winter" (July-August) temperature in Brisbane is $11-21^{\circ} \mathrm{C}\left(51.8-69.8^{\circ} \mathrm{F}\right)$ whereas in Melbourne it is $6.5-14.2^{\circ} \mathrm{C}$ $\left(43.7-57.6^{\circ} \mathrm{F}\right)$. This makes outdoor swimming pools unviable to an extent due to the cost of heating them with natural gas through winter.

4. "S class" is for freestyle, backstroke and butterfly events, SB denotes breaststroke and SM is for individual medley.

5. Important to note here that Carly's inclusion of deaf people is not a contradiction with the emphasis above that everyone except Debbie "only included athletes who could be classified." That is because at the domestic level swimming Australia uses the classifications SB SM and S15 for people who are deaf to compete at State and National teams, but this does not articulate into the Paralympic pathway. As Carly explained Swimming Australia does not support National deaf teams but does provide this group with a similar pathway at domestic competitions.

\section{Acknowledgments}

Hammond received funding from the Commonwealth Government of Australia as part of the Australian Research Training Program to complete this work as a Doctoral Student at Monash University.

\section{References}

Arribas-Ayllon, M., \& Walkerdine, V. (2010). Chapter 6: Foucauldian discourse analysis. In C. Willig \& W. Stainton-Rogers (Eds.), The SAGE Handbook of Qualitative Research in Psychology (pp. 91-108). London, UK: Sage. doi:10.4135/9781848607927

Barton, L. (1997). Inclusive education: Romantic, subversive or realistic? International Journal of Inclusive Education, 1(3), 231-242. doi:10. 1080/1360311970010301

Braye, S., Dixon, K., \& Gibbons, T. (2013). 'A mockery of equality’: An exploratory investigation into disabled activists' views of the paralympic games. Disability \& Society, 28(7), 984-996. doi:10.1080/ 09687599.2012.748648

Brittain, I. (2016). The paralympic games explained (2nd ed.). Abingdon, Oxon: Routledge.

Brown, W. (2015). Undoing the demos: Neoliberalism's stealth revolution. Boston, MA: MIT Press. 
Brown, W. (2018). Where the fires are. Soundings, 68(68), 14-25. doi:10. 3898/136266218822845619.

Bush, A.J., \& Silk, M.L. (2012). Politics, power \& the podium: Coaching for paralympic performance. Reflective Practice, 13(3), 471-482. doi:10.1080/14623943.2012.670109

Cregan, K., Bloom, G.A., \& Reid, G. (2007). Career evolution and knowledge of elite coaches of swimmers with a physical disability. Research Quarterly for Exercise and Sport, 78(4), 339-350. PubMed ID: 17941538 doi:10.1080/02701367.2007.10599431

Dean, M. (1995). Governing the unemployed self in an active society. Economy and Society, 24(4), 559-583. doi:10.1080/03085149500000025

Dean, M. (2010). Governmentality: Power and rule in modern society (2nd ed.). London, UK: Sage.

DeLuca, C. (2013). Toward an interdisciplinary framework for educational inclusivity. Canadian Journal of Education, 36(1), 305-348.

Department of Human Services, State of Victoria. (2012). Reporting it right: Media guidelines for portraying people with a disability. Retrieved from http://www.dhs.vic.gov.au/_data/assets/pdf_file/ 0006/754350/DHS_MediaGuides_Print.pdf

Fitzgerald, M. (2018). Sport is not for all: The transformative (im) possibilities of sport for young disabled people. In R.A. Dionigi, \& M. Gard (Eds.), Sport and physical activity across the lifespan (pp. 175-191). London: Springer Nature.

DePauw, K. (1997). The (in) visibility of disability: Cultural contexts and "sporting bodies". Quest, 49(4), 416-430. doi:10.1080/00336297. 1997.10484258.

Foucault, M. (1991). Governmentality. In G. Burchel, C. Gordon, \& P.G. Miller (Eds.), The foucault effect: Studies in governmentality (pp. 87-104). Chicago, IL: University of Chicago Press.

Foucault, M., Davidson, A.I., \& Burchell, G. (2008). The birth of biopolitics: Lectures at the collège de france, 1978-1979. Basingstoke, UK: Palgrave Macmillan.

Gard, M., Dionigi, R.A., \& Dionigi, C. (2018). From a lucky few to the reluctant many: Interrogating the politics of sport for all. In Sport and physical activity across the lifespan (pp. 67-89). Springer.

Goggin, G., \& Newell, C. (2000). Crippling paralympics? Media, disability and olympism. Media International Australia incorporating Culture and Policy, 97(1), 71-83. doi:10.1177/1329878X0009700110

Goggin, G., \& Newell, C. (2005). Disability in Australia: Exposing a social apartheid. Sydney, Australia: UNSW Press.

Goodley, D. (2014). Dis/ability studies: Theorising disablism and ableism. Abingdon, Oxon: Routledge.

Goodley, D. (2017). Disability studies: An interdisiplinary introduction (2nd ed.). London, UK: Sage.

Goodley, D., Lawthom, R., \& Runswick-Cole, K. (2014). Dis/ability and austerity: Beyond work and slow death. Disability \& Society, 29(6), 980-984. doi:10.1080/09687599.2014.920125

Goodley, D., \& Runswick-Cole, K. (2015). Big society? Disabled people with the label of learning disabilities and the queer(y)ing of civil society. Scandinavian Journal of Disability Research, 17(1), 1-13. doi:10.1080/15017419.2014.941924

Green, M., \& Houlihan, B. (2005). Elite sport development: Policy learning and political priorities. London, UK: Routledge.

Hall, C.M. (2006). Urban entrepreneurship, corporate interests and sports mega-events: The thin policies of competitiveness within the hard outcomes of neoliberalism. The Sociological Review, 54(Suppl. 2), 59-70. doi:10.1111/j.1467-954X.2006.00653.x

Hammond, A. (2019). The mainstreaming of disability swimming in Australia, 1990-2016 Sporting Traditions, 36(1), 43-62.

Hammond, A., \& Jeanes, R. (2018). Federal government involvement in Australian disability sport: 1981-2015. The International Journal of the History of Sport, 35(5), 431-447.doi:10.1080/09523367.2017. 1337000

Harwood, V., \& Rasmussen, M.L. (2004). Studying schools with an 'ethics of discomfort'. In Dangerous coagulations (pp. 305-321). New York, NY: Peter Lang.

Hayhurst, L.M.C., Wilson, B., \& Frisby, W. (2010). Navigating neoliberal networks: Transnational internet platforms in sport for development and peace. International Review for the Sociology of Sport, 46(3), 315-329. doi:10.1177/1012690210380575

Horne, J. (2005). Sport in consumer culture. Basingstoke, Hampshire: Palgrave Mcmillian.

Howe, P.D. (2008a). The cultural politics of the paralympic movement: Through an anthropological lens. Abringdon, Oxon: Routledge.

Howe, P.D. (2008b). The tail is wagging the dog: Body culture, classification and the paralympic movement. Ethnography, 9(4), 499-517. doi:10.1177/1466138108096989

Howe, P.D., \& Jones, C. (2006). Classification of disabled athletes: (dis) empowering the paralympic practice community. Sociology of Sport Journal, 23(1), 29-46. doi:10.1123/ssj.23.1.29

Howe, P.D., \& Kitchin, P.J. (2017). Managing paralympic bodies: The technology of classification and its impact on (dis)abled athletes. In S. Darcy, D. Adair, \& S. Frawley (Eds.), Managing the pralympics (pp. 113-132). London, UK: Springer Nature.

Howe, P.D., \& Silva, C.F. (2017). The fiddle of using the paralympic games as a vehicle for expanding [dis]ability sport participation. Sport in Society, 21(1), 125-136. doi:10.1080/17430437.2016. 1225885

Jeanes, R., Spaaij, R., Magee, J., Farquharson, K., Gorman, S., \& Lusher, D. (2017). 'Yes we are inclusive': Examining provision for young people with disabilities in community sport clubs. Sport Management Review, 21(1), 38-50. doi:10.1016/j.smr.2017.04.001

Jeanes, R., Spaaij, R., Magee, J., Farquharson, K., Gorman, S., \& Lusher, D. (2018). Developing participation opportunities for young people with disabilities? Policy enactment and social inclusion in Australian junior sport. Sport in Society, 22(6), 986-1004. doi:10.1080/ 17430437.2018.1515202

Jeanes, R., Spaaij, R., Magee, J., Farquharson, K., Gorman, S., \& Lusher, D. (2019). Developing participation opportunities for young people with disabilities? Policy enactment and social inclusion in Australian junior sport. Sport in Society. Advance online publication.10.1080/ 17430437.2018.1515202

Jones, C., \& Howe, P.D. (2005). The conceptual boundaries of sport for the disabled: Classification and athletic performance. Journal of the Philosophy of Sport, 32(2), 133-146. doi:10.1080/00948705.2005. 9714678

Kitchin, P.J., \& Crossin, A. (2018). Understanding which dimensions of organisational capacity support the vertical integration of disability football clubs. Managing Sport and Leisure, 23(1-2), 28-47. doi:10. 1080/23750472.2018.1481764

Kitchin, P.J., \& Howe, P.D. (2014). The mainstreaming of disability cricket in England and Wales: Integration 'one game' at a time. Sport Management Review, 17(1), 65-77. doi:10.1016/j.smr.2013. 05.003

Kumari Campbell, F.A. (2001). Inciting legal fictions-disability's date with ontology and the ableist body of the law. Griffith Law Review, $10,42$.

Kumari Campbell, F.A. (2009). Contours of ableism. The production of disability and abledness. Basingstoke, UK: Palgrave Macmillian.

Leahy, D. (2012). Assembling a health [y] subject (Unpublished doctoral dissertation). Deakin University, Burwood. Retrieved from http://hdl. handle.net/10536/DRO/DU:30048464 
McMahon, J., \& Zehntner, C. (2014). Shifting perspectives: Transitioning from coach centered to athlete centered. Journal of Athlete Centered Coaching, 1(2), 1-19.

McRuer, M. (2016). Compulsory able-bodiedness and queer/disabled existence. In L.J. Davis (Ed.), The disability studies reader (5 ed., pp. 396-405). New York, NY: Routledge.

Miller, P., \& Rose, N. (2008). Governing the present: Administering economic, social and personal life. Cambridge, UK: Polity Press.

Parnell, D., May, A., Widdop, P., Cope, E., \& Bailey, R. (2018). Management strategies of non-profit community sport facilities in an era of austerity. European Sport Management Quarterly. Advance online publication. doi:10.1080/16184742.2018.1523944

Partington, M., \& Cushion, C. (2013). An investigation of the practice activities and coaching behaviors of professional top-level youth soccer coaches. Scandinavian Journal of Medicine \& Science in Sports, 23(3), 374-382. PubMed ID: 22092356 doi:10.1111/j.16000838.2011.01383.x

Peers, D., Spencer-Cavaliere, N., \& Eales, L. (2014). Say what you mean: Rethinking disability language in. Adapted Physical Activity Quarterly, 31, 265-282. PubMed ID: 25028477 doi:10.1123/apaq.2013-0091.

Phillips, M. (2000). From sidelines to centre field: A history of sports coaching in Australia. Sydney, Australia: University of New South Wales Press.

Phillips, M. (2008). Swimming Australia: One hundred years. Sydney, Australia: UNSW press.

Purdue, D.E., \& Howe, P.D. (2013). Who's in and who is out? Legitimate bodies within the paralympic games. Sociology of Sport Journal, 30(1), 24-40. doi:10.1123/ssj.30.1.24

Richter, K.J., Adams-Mushett, C., Ferrara, M.S., \& McCann, B.C. (1992). Llntegrated swimming classification: A faulted system. Adapted Physical Activity Quarterly, 9, 5-13. doi:10.1123/apaq.9.1.5

Schalk, S. (2016). Reevaluating the supercrip. Journal of Literary \& Cultural Disability Studies, 10(1), 71-86. doi:10.3828/jlcds. 2016.5

Shapiro, J.P. (1994). No pity: People with disabilities forging a new civil rights movement. New York, NY: Times Books.

Shenk, T. (2015). Booked \#3: What exactly is neoliberalism? Dissent Magazine. Retrieved from https://www.dissentmagazine.org/blog/ booked-3-what-exactly-is-neoliberalism-wendy-brown-undoing-thedemos

Shogan, D. (1998). The social construction of disability: The impact of statistics and technology. Adapted Physical Activity Quarterly, 15(3), 269-277. doi:10.1123/apaq.15.3.269

Shogan, D. (1999). The making of high-performance athletes: Discipline, diversity, and ethics. University of Toronto Press.
Silva, C.F., \& Howe, P.D. (2012). The (in)validity of supercrip representation of Paralympian athletes. Journal of Sport and Social Issues, 36(2), 174-194. doi:10.1177/0193723511433865

Smith, B., \& Bundon, A. (2017). Disability models: Explaining and understanding disability sport in different ways. In I. Brittain \& A. Beacom (Eds.), The Palgrave Handbook of Paralympic Studies (pp. 15-34). Basingstoke: Palgrave. doi:10.1057/978-1-137-47901-3_2

Smith, B., Bundon, A., \& Best, M. (2016). Disability sport and activist identities: A qualitative study of narratives of activism among elite athletes' with impairment. Psychology of Sport and Exercise, 26, 139-148. doi:10.1016/j.psychsport.2016.07.003

Smith, B., \& Sparkes, A.C. (2013). Qualitative research methods in sport, exercise and health: From process to product. Abingdon, Oxon: Routledge.

Sparkes, A.C., \& Smith, B. (2013). Qualitative research methods in sport, exercise and health: From process to product. London, UK: Routledge.

Swimming Australia. (2013). Classification procedures manual. Retrieved from https://www.swimming.org.au/getattachment/de58141e-8ccc-46e0903a-7292199fd648/Swimming_Australia_Classification_Procedures_ Manual_August2013.pdf.aspx?chset=bf5d921d-21b4-4dc4-a87e$\mathrm{d} 45659418 \mathrm{~d} 7 \mathrm{f} \&$ disposition=attachment

Thomas, C. (2007). Sociologies of disability and illness: Contested ideas in disability studies and medical sociology. Basingstoke: Palgrave Macmillan.

Townsend, R.C., Cushion, C.J., \& Smith, B. (2018). A social relational analysis of an impairment-specific mode of disability coach education. Qualitative Research in Sport, Exercise and Health, 10(3), 346-361. doi:10.1080/2159676X.2017.1407355.

Tweedy, S.M., Beckman, E.M., \& Connick, M.J. (2014). Paralympic classification: Conceptual basis, current methods, and research update. PM\&R, 6(Suppl. 8), S11-S17. doi:10.1016/j.pmrj.2014.04.013

Wedgwood, N. (2014). Hahn versus guttmann: Revisiting 'sports and the political movement of disabled persons'. Disability \& Society, 29(1), 129-142. doi:10.1080/09687599.2013.776488

Wickman, K. (2007). Bending mainstream definitions of sport, gender and ability ( $\mathrm{PhD}$ thesis). Umeå University, Umeå, Sweden.

Woods, M. (2010). Inclusion is best practice. Journal of the Australian Swimming Coaches and Teachers Association, 27(1), 46.

Woods, M. (2015). The inclusive swimming framework. Retrieved from https://www.swimming.org.au/Assets/Policies/InclusiveSwimming Framework.aspx

Zehntner, C. (2016). The way that things are done around here: An investigation into the organisational and social structures that contribute to structural power within the Australian swim coach education pathway (Doctor of philosophy). University of Tasmania, Tasmania, Australia. 